\title{
La enseñanza del terrorismo de estado mediante la microhistoria
}

\section{The teaching of state terrorism by microhistory}

COMUNICACIÓN

\section{Leopoldo Muza}

Instituto Superior de Formación Docente y Técnica № 126, Salto, Argentina.

leomuza@gmail.com

Recibido: mayo del 2016

Aceptado: septiembre del 2016

\section{Resumen}

El presente trabajo narra una secuencia didáctica en Nivel Terciario. Partiendo de la pregunta: ¿Cómo puede enseñarse el terrorismo de estado con aportes de la microhistoria? El Trabajo da cuenta de los aportes de la microhistoria a la enseñanza de los hechos recientes de nuestro país. Cuando se acerca la temática a la realidad de la ciudad, cuando los nombres llegan a familiares o a amigos se hace más cercana la dictadura.

Palabras claves: terrorismo; estado; dictadura; memoria; TIC.

\begin{abstract}
This paper recounts a didactic sequence at tertiary level. Based on the question: How to teach state terrorism with contributions from microhistory? The work explains the contributions of microhistory in the teaching of the recent facts in our country. When the subject comes to the reality of the city, where the names reach family or friends the dictatorship becomes more real.
\end{abstract}

Keywords: technology; terrorism; state; dictatorship; memory. 
...¿Cambiarán las escuelas de la manera en que se les pide, a la luz de estos nuevos desafíos y oportunidades, de estos nuevos riesgos y promesas emergentes? Ojalá. Pero que cambien o no está menos ligado a las posibilidades tecnológicas, yo creo, que a los límites del deseo y la imaginación... (Burbules, 2008).

\section{El uso de la tecnología para la comprensión del impacto local del terrorismo de estado}

Esta propuesta didáctica intenta dar respuesta a la siguiente problemática: ¿Cómo puede enseñarse el terrorismo de estado con aportes de la microhistoria? El trabajo constituye una narración pedagógica de distintos tópicos vinculados con la planificación y concreción de la una secuencia didáctica trabajada con alumnos de Nivel Terciario durante el primer cuatrimestre del ciclo lectivo 2016.

Mediante diversas metodologías buscaré responder a la pregunta- consigna. El primer rasgo identitario que se intenta explorar en la clase es la vinculación etaria entre los alumnos y los detenidos desaparecidos.

Un dato impacta a la mirada de los alumnos: uno de cada diez detenidosdesaparecidos tenía entre 16 y 20 años según el informe Nunca Más. (Conadep, 1984). Esta temática es el primer punto de trabajo con la utilización de un material multimedia. Dicho trabajo fue elaborado por la Comisión Municipal de Juventud y se llamó: Liberarte, Cultura es Memoria.

La planificación de la que parte esta propuesta tenía como primer objetivo trabajar la identidad que, al aplicarse en el Nivel Superior, se dio por supuesto que los alumnos tenían ciertos saberes previos al respecto de su concepción. Sin embargo, al comenzar a trabajar directamente sobre la temática "Apropiación de niños en la última dictadura cívico - militar", los trabajos no expresaban la profundidad temática que buscaba como docente. De esta manera, decidí retomar el concepto de identidad y trabajarlo desde la identidad de una comunidad.

Tomé la iniciativa de alterar la secuencia tal como la había planificado para tener una correcta lectura de los saberes previos que exploran los alumnos y que resultaba fundamental para el éxito de la secuencia didáctica. Así, se buscó retomar la idea de Ausubel y otros (1978) al definir como aprendizaje significativo, el que se produce cuando el alumno logra establecer relaciones entre los nuevos conceptos y los conocimientos ya existentes, creando un conocimiento propio. De este modo: 
La adquisición de información nueva depende en alto grado de las ideas pertinentes que ya existen en la estructura cognitiva y el aprendizaje significativo de los seres humanos ocurre a través de una interacción de la nueva información con las ideas pertinentes que existen en la estructura cognitiva. El resultado de la intención que tiene lugar entre el nuevo material que se va a aprender y la estructura cognitiva existente constituye una asimilación de significados nuevos y antiguos para formar una estructura cognitiva altamente diferenciada (Ausubel y otros, 1978).

Desde este lugar, se trabajó una nueva pregunta disparadora: ¿Pensás que es posible que se produjera una dictadura en nuestro país hoy? Para analizarlo nos apoyamos en un material fílmico: la película La Ola (2008), incluida en el Archivo Fílmico Pedagógico Jóvenes y Escuelas.

\section{Desarrollo: una posible respuesta}

La Ley Nacional No 25633/02 y la Ley Provincial $N^{\circ} 11782 / 96$ nos convocan a trabajar sobre el ejercicio permanente en el derecho a la memoria, a la verdad y a la justicia. En el artículo $1^{\circ}$ de la Ley Provincial se dispone que "en todos los establecimientos educativos dependientes de la Dirección General de Cultura y Educación de la Provincia de Buenos Aires, se realicen actividades que contribuyan a la información y a la profundización del conocimiento por parte de los educandos, del golpe de Estado perpetrado el 24 de marzo de 1976 y las características del régimen que el mismo impuso." (Ley Provincial № 11782/96).

La forma en que se propuso que los alumnos den una respuesta a la problemática planteada, fue a través de la integración y utilización de las tecnologías de la información y la comunicación (TIC). También se apuntó al uso de recursos básicos del periodismo tal como la crónica y el perfil. Usando como disparador material multimedia, fílmico y el uso de la red social Facebook con el objetivo de lograr la retroalimentación de los conceptos de los alumnos. Dicha interacción se complementaba, en la propuesta, con el diálogo cara a cara en el aula.

Para conceptualizar las prácticas educativas con TIC, se tomó a Coll y otros (2008) en su perspectiva constructivista de orientación sociocultural:

Por un lado, porque desde este marco se subraya la idea de que las TIC constituyen herramientas o instrumentos mediadores de la actividad mental constructiva de los alumnos y de los procesos de enseñanza, lo cual lleva de forma natural a poder plantear la cuestión de cuáles son los usos de esas herramientas o instrumentos. Por otro, porque esta perspectiva propone un espacio en el que esos usos pueden buscarse e identificarse: la actividad conjunta llevada a cabo por profesor y alumnos alrededor de las actividades, las tareas y los contenidos que vertebran el trabajo, la enseñanza y el aprendizaje en el aula . (p. 3).

Esa actividad conjunta entre docente y alumnos fue posible. Si bien la utilización de 
Facebook como foro suele complejizar la corrección y el cierre de la actividad, se generó esa alternativa, teniendo en cuenta lo que González Vargas (2008) en su texto sobre Jenkins recomienda:

no tenerle miedo a la tecnología y dejar que los niños y jóvenes aprendan a usarla debido a la importancia de adquirir competencias y habilidades que permitan a los niños y jóvenes trabajar en ese mundo (que será el que les corresponderá vivir como adultos). Todo lo contrario a lo que suele hacerse en educación donde ante un problema y debido al desconocimiento de estos medios, solo encontramos, como respuesta más usada, la prohibición de usarlos. (p. 1.)

\section{Derechos humanos e identidad}

Desde el punto de vista pedagógico el desafío fue recuperar la historia reciente de nuestro país, vinculada con nuestro territorio local a fin de lograr mayor cercanía de la temática a los alumnos. La secuencia se trabajó desde la Pedagogía de la Memoria. Esta línea de trabajo se relacionaba con uno de los objetivos de la secuencia en que los alumnos: "aborden pedagógicamente el concepto de Derechos Humanos de un modo integrador dando cuenta de su complejidad y profundizando en la comprensión de su significado".

El trabajo se realizó desde la concepción de la identidad de nuestra comunidad y su vínculo con la última dictadura. El terrorismo de Estado desde el territorio fue la problemática que ordenó la propuesta de clase.

De esta manera, en la práctica se profundizó mediante el uso de una presentación multimedia y de un video realizado por alumnos de una escuela secundaria de Salto: llamado "Como reguero de pólvora" (2009), en la reconstrucción de la memoria local y las huellas que la dictadura ha dejado en la comunidad.

Este documental comenzaba con la noticia de la aparición de tres cuerpos sin identificación en el año '76 en la localidad y los jóvenes de Salto se proponían la reconstrucción de lo sucedido. Con este fin, se investigaba e interrogaban y realizaban entrevistas a vecinos y representantes de la comunidad para encontrar las respuestas a sus preguntas.

Dos líneas de trabajo histórico - periodístico quedaron abiertas: la primera era la de la Crónica de los asesinatos en el camino rural. Se proponía ampliar la investigación del documental "Como reguero de pólvora"; la segunda, llevada adelante por parte de aquellos que no trabajaban en este primer tema profundizaron en la investigación de perfiles que se esbozaba en el video multimedia Liberarte (2005). La metodología elegida -en esta últimafue el trazado de perfiles de los ciudadanos desaparecidos o asesinados por el terrorismo de estado, realizando biografías -que permitan reconstruir parte de sus vidas como lo han hecho (en una escala de investigación mucho más profunda) Abuelas de Plaza de Mayo.

Este trabajo iniciado en el aula concluía con un trabajo grupal orientado por el 
docente, quien, además, realizaba el cierre de la actividad. A su vez, el grupo de Facebook se utilizó como aula extendida para que los alumnos publiquen los link con sus producciones y participen en el análisis de lo realizado por sus compañeros.

El producto final fue un conjunto de materiales analógicos y digitales que sirvieron -y servirán- como insumo de divulgación histórica; es decir que podría ser tomado por aquellos ciudadanos, estudiantes u organizaciones que quieran retomar el trabajo de investigación, o bien utilizarlo como apoyo para posteriores investigaciones.

Asimismo, resultaba también una herramienta de información útil acerca de las problemáticas de derechos humanos que se presentaran en la ciudad, y que algunos ciudadanos podrían desconocer, o en el mejor de los casos, sepan sobre su existencia pero no dónde buscar dicha información.

Cuando se desea integrar TICs en el aula, uno de los grandes desafíos se juega justamente en el terreno de la gestión de la clase, donde esa planificación por parte del docente deberá llevarse a cabo.

Para ello tuve en cuenta algunas de las cuestiones necesarias para gestionar las actividades de enseñanza y las tareas de aprendizaje señaladas por Feldman (2008), y se incorporaron algunas ligadas a la integración de TIC, entre las que escogí las siguientes relacionándolas con la secuencia:

-Promover la participación en las tareas de aprendizaje en los trabajos colaborativos intervenidos con TIC.

-Pensar y plantear la clase a través de situaciones en las que el conocimiento se distribuye entre docente y alumnos.

-La distribución del contenido espacial y temporal a través de herramientas como imágenes y videos.

\section{Pensar la dictadura hoy}

La última parte de esta propuesta parte de un desafío inquietante: analizar la existencia de los regímenes totalitarios desde el presente mediante una nueva pregunta disparadora: ¿Pensás que sería posible que se produjera una dictadura en nuestro país hoy?

El pensador italiano Primo Levi invita a reflexionar sobre cuestiones de este tipo. Al respecto, se recuerda la frase: si la humanidad ya estuvo allí, la humanidad puede volver. En esta perspectiva, en el poema "Si esto es un hombre" puede leerse:

Reflexionen y recuerden que todo esto sucedió / que pasaron estas cosas: Que yo les ordeno grabarlas en su corazón/ $\mathrm{Y}$ las repetirán a sus hijos / al regresar a sus casas y al ir en los caminos / y al acostarse y al levantarse/ Y si ustedes callan 
se destruyan sus casas / y les aflija la enfermedad desde los pies a la cabeza / y también sus descendientes les volteen la cara. (Levi, 1947, p. 5).

Primo Levi nos habla acerca la necesidad de ejercer la memoria sin eufemismos. Si no recordamos los crímenes aberrantes cometidos por la humanidad no merecemos una casa, tener salud y ni que nuestros descendientes escuchen nuestras palabras.

Esta reflexión nos introduce en el Trabajo Práctico que se realiza luego de ver la película propuesta. En "La Ola" un profesor, Rainer Wenger, encuentra en un juego que se propone sostener durante una semana, la posibilidad de reconocerse a sí mismo como conductor de un grupo juvenil, al que intentará hacer vivir en sus propios cuerpos la experiencia del totalitarismo desde la perspectiva de quienes la historia ha señalado como los victimarios.

La película permite realizar sin mayor esfuerzo un paralelismo con el pasado reciente en nuestro país. El diccionario de la Real Academia Española define a la autocracia como "sistema de gobierno en el cual la voluntad de una sola persona es la suprema ley". Sobre esta palabra trabajará el profesor Rainer Wenger, y sobre los interrogantes que sus discípulos le plantean desde el primer intercambio de ideas: ¿cómo fue posible que un gobierno autocrático haya logrado miles de voluntades, convocando a unos seres humanos al exterminio de otros? ¿Eso sería posible hoy?

Wenger intentó producir una experiencia que fuera significativa para sus alumnos. Pero sus acciones pusieron en riesgo a los jóvenes que tenía bajo su responsabilidad.

La experiencia fue transformada en un experimento que poco tuvo que ver con hacer pasar por la sensibilidad y el pensamiento esos fragmentos desgarradores de la historia de la humanidad. Y sobre el final se desencadena la tragedia.

\section{La voz de los jóvenes}

La película habilita la discusión sobre el presente y nos conecta con otro de los objetivos de la secuencia: que los alumnos logren una responsabilidad ética y política de la ciudadanía a partir del conocimiento y la comprensión del significado histórico de lo sucedido durante la última dictadura cívico - militar en nuestro país.

Ante la pregunta: ¿Pensás que sería posible que se produjera una dictadura en nuestro país hoy?, los alumnos debatieron en clase y luego volcaron sus reflexiones en el aula extendida: pusieron el acento en que "la película nos da una alerta de lo posible a ser repetido". Ven ejemplos de totalitarismos en la política mundial que les llegan mediante los medios masivos, "como ISIS" contesta una de ellas. Otro introduce un nuevo elemento de análisis: "la tecnología haría mucho más fácil que la dictadura crezca".

Las razones que encuentran los alumnos para afirmar que una dictadura no puede producirse hoy no tienen que ver con la fortaleza de nuestro sistema democrático, sino con 
que "las fuerzas militares están muy débiles". En el mismo sentido otro alumno afirma: "se ha desmoronado el Ejército, ya no es tan fuerte ni tiene tanto poder como antes". (Muza, 2016).

La apuesta a una sociedad democratizada solo surge en una de las respuestas esbozadas por los alumnos: "todos estamos más sociables con el otro y ya no se piensa como antes". La película cumplió su objetivo: abrió la puerta al debate y el intercambio de ideas.

\section{Facebook como Aula Extendida}

Las dos problemáticas que nos permitieron trabajar esta propuesta pedagógica se resolvieron en Facebook, como aula extendida. Una ágora pública de la posmodernidad, la red social permitió un uso escolar que excedió el tiempo del aula.

En este sentido la Universidad Simón Bolívar de Colombia en su página oficial definió el aula extendida como un "espacio de comunicación e interacción educativa que permite al docente complementar su práctica pedagógica, social y cultural fuera del aula de clase". (Pascolini y Fernández).

A partir de esta definición podríamos decir que el Aula Extendida se constituye en un espacio donde enriquecer y ampliar los contenidos y las experiencias del aula presencial, donde dialogan la teoría y la práctica y donde los recursos didácticos adquieren significado.

El uso de Facebook puede ser no solo un apoyo a la presencialidad -ya que el aula no sólo contiene "materiales teóricos"- sino también un espacio de comunicación propia de los vínculos que se establecen en todo proceso de enseñanza y de aprendizaje.

Cabe señalar, en este momento, la importancia de la acción de mediador del docente: acción, como acto intencional, y mediada por el uso de herramientas culturales, que requieren de los sujetos, su interpretación simbólica. En los espacios virtuales, las herramientas tecnológicas están mediatizadas por la alfabetización tecnológica y el valor que le confieren los destinatarios. Por lo tanto, el desafío docente es encontrar los recursos para que esta mediatización sea efectiva.

La era digital nos ofrece la oportunidad de cambiar el paradigma pedagógico centrado en la figura del docente bajo métodos estandarizados de enseñanza, hacia uno nuevo que priorice las capacidades cognitivas y al trabajo colaborativo. Aquí la participación activa del estudiante está en la resolución de problemas, el análisis de casos, la reflexión crítica y la búsqueda del saber.

\section{Conclusión: las preguntas nos ayudan a caminar}


La actividad comenzó con una pregunta: ¿Cómo puede enseñarse el terrorismo de estado con aportes de la microhistoria? En el desarrollo del texto puede observarse la forma en que la microhistoria puede aportar a la enseñanza de los hechos recientes de nuestro país. De la práctica se puede deducir que cuando se acerca la temática a la realidad de la ciudad, trabajando sobre la biografía de aquellos saltenses afectados por el terrorismo de estado, se hace más cercana la dictadura.

Para Gribaudi (1996) lo micro supone una técnica intensiva y el ideal es la reconstitución total del tejido social. De esta forma el rol de los jóvenes no es de receptores pasivos de historias pasadas, sino que son los alumnos los que re-elaboran las memorias de su localidad en sintonía con el presente para pensar no solo lo que pasó sino otras formas de presentes y futuros posibles.

Algunas preguntas resurgieron durante la clase: ¿Que pasó durante la última dictadura? ¿Por qué se denomina "terrorismo de Estado a ese hecho histórico? De ahí que sea crucial para cualquier desarrollo de "políticas educativas de la memoria" la interrogación acerca de cómo indagar en el pasado desde el presente: qué recordar, cómo recordar y para qué recordar. La transmisión del pasado reciente en la escuela, a través de la labor de los educadores en tanto portadores de un conocimiento específico y sujetos de derecho, implica activar estas preguntas para que la pedagogía de la memoria habilite vínculos significativos con el pasado que permitan imaginar futuros más justos.

En cuanto a los trabajos realizados por los alumnos, la dimensión micro histórica de las investigaciones les permite una mirada menos abstracta y a la vez menos esquemática y estereotipada que la que logran aprender en los textos académicos y otras narraciones disponibles.

Cuando los alumnos presentan las producciones, son portadores de la palabra, cambian su función de receptores para escuchar y aprender, ahora hablan y también pueden enseñar.

Desde Pensar la Dictadura (2010) el Ministerio de Educación nos motiva a preguntarnos: ¿Qué implica educar en y para los derechos? ¿Por qué se piensa que los derechos humanos son una cuestión educativa? ¿De qué manera aparece la cuestión de los derechos humanos en nuestra formación y en nuestras prácticas educativas?

¿Por qué es fundamental contar con una formación en derechos? ¿Qué estrategias pedagógicas nos damos o podemos darnos para educar en derechos? ¿Qué recursos consideramos necesarios para promover los derechos en el aula y en las escuelas donde desarrollamos nuestra tarea? Quizá como Silvio Rodríguez en su canción "Escaramujo", la clave como educadores es pensar: "Yo vivo de preguntar, saber no puede ser lujo".

\section{Referencias Bibliográficas}


Ausubel, D., Novak, J., \& Hanesian, H. (1978). Educational Psychology: A Cognitive View (2nd Ed.). New York: Holt, Rinehart \& Winston.

Burbules, N. C. (2008). Riesgos y promesas de las TIC en la educación. ¿Qué hemos aprendido en estos últimos diez años? En Las TIC: del aula a la agenda política. Buenos Aires: Unesco.

CONADEP (1984). Informe "Nunca Más". Buenos Aires: Eudeba.

Coll, C., Mauri, T. y Onrubia, J. (2008). Análisis de los usos reales de las tics en contextos educativos formales: una aproximación sociocultural. Revista Electrónica de Investigación Educativa (10).

EEAN¹ (2009) "Como reguero de pólvora". Gahan (Salto). Programa "Jóvenes y Memoria". Documental audiovisual.

Feldman, D. (2010). Didáctica general. Aportes para el desarrollo curricular. Buenos Aires: Ministerio de educación de la Nación.

González Vargas, B. (2008). Henry Jenkins y la Cultura Participativa en ambientes escolares. Recuperado de:

http://aulapostitulo.educacion.gob.ar/archivos/repositorio//3750/3788/Henry Jenkins y la Cultura Participativa en ambientes escolares.pdf

Gribaudi, M. (1996). Écheile, pertinence, configuration. En Revel, J., D'Échelles, J. La micro-analyse a l'expérience. París: Gailimard Le Seuil.

Ley Nacional № 25633/02.

Ley Provincial № 11782/96.

Ministerio de Educación de Nación (2010). Pensar la Dictadura: el terrorismo de Estado en Argentina. Preguntas, Respuestas y Propuestas para su Enseñanza. Buenos Aires: Programa Educación y Memoria.

Muza, L. y otros (2005). Liberarte. Cultura es Memoria. Salto: Comisión Municipal de Juventud. Recuperado de: https://www.youtube.com/watch?v=ipEOD06KMZU

Muza, L. (2016). "Apuntes de Cátedra. Trabajo práctico sobre la película La Ola". Practica Profesionalizante. ISFDyT №126. Primer cuatrimestre 2016.

Levi, P. (1947). Si esto es un hombre. Ciudad Turín, París, Italia: Editorial Giulio Einaudi

Pascolini, R. y Fernández, A. Las Aulas Virtuales. Dos enfoques para su implementación. Colombia: Universidad Simón Bolívar. Recuperado de: http://campus.unla.edu.ar/las-aulas-virtuales-dos-enfoques-para-suimplementacion/

Película La Ola (2008). Director: Dennis Gansel. Guion: Dennis Gansel, Peter Thorwart. Alemania. 


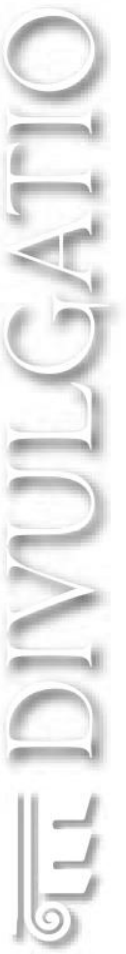

